\title{
O IMPACTO DA PANDEMIA DO NOVO CORONAVÍRUS NA JORNADA DE TRABALHO DOS PROFISSIONAIS DE PUBLICIDADE E PROPAGANDA
}

\section{THE IMPACT OF THE NEW CORONAVIRUS PANDEMIC ON THE WORKING DAY OF ADVERTISING AND ADVERTISING PROFESSIONALS}

\author{
Josiene Severo Noronha1 ${ }^{1}$, Davi Carrer²
}

\author{
Submetido: 03/12/2020 \\ Aprovado: 19/01/2021
}

\begin{abstract}
RESUMO:
Durante a pandemia do novo coronavírus, o setor de Publicidade e Propaganda precisou se adequar para realizar o seu trabalho em home office. Saber qual foi a realidade dos profissionais devido às mudanças, quais foram as adaptações que tiveram que enfrentar, os impactos em seus cotidianos e se esse sistema foi apenas momentâneo devido à pandemia ou se pode se tornar uma prática constante nas agências de publicidade, são os objetivos deste artigo. Para isso, foram abordados a relação de trabalho home office antes e durante a pandemia, a estrutura de uma agência de Publicidade e quais vantagens e desvantagens da implementação do home office, tanto para os colaboradores quanto para as agências e o funcionamento do mercado e jornada de trabalho nas organizações, a fim de entender quais meios de trabalho podem ser adaptados para a realidade dos profissionais de comunicação. Foi realizado, também, uma pesquisa com alguns colaboradores que trabalham em agências de Publicidade de Santa Catarina, dando ênfase em perguntas que abordaram a implementação do home office durante a pandemia. Baseado nas informações coletadas, verificou-se que o impacto profissional, pessoal e emocional das mudanças bruscas geradas pela pandemia foram fatores que pesaram para que o home office e jornadas de trabalho alternativas em momentos de crise devam ser melhor avaliados para uma adequação que evite gerar dificuldades emocionais aos colaboradores, principalmente em momentos de estresse, ansiedade e incertezas, como foi o caso da pandemia.
\end{abstract}

PALAVRAS-CHAVE: Home office. Publicidade e propaganda. Coronavírus.

\begin{abstract}
During the pandemic of the new coronavirus, the Advertising sector needed to adapt to carry out its work in the home office. Knowing what was the reality of the professionals due to the changes, what were the adaptations they had to face, the impacts on their daily lives and if this system was only momentary due to the pandemic or if it can become a constant practice in advertising agencies, are the objectives of this article. For this, the home office work relationship was addressed before and during the pandemic, the structure of an Advertising agency and what are the advantages and disadvantages of implementing the home office, both for employees and for the agencies and the functioning of the market and working hours organizations in order to understand which means of work can be adapted to the reality of communication professionals. A survey was also carried out with some employees who work in Advertising agencies in Santa Catarina, emphasizing questions that addressed the implementation of the home office during the pandemic. Based on the information collected, it was found that the professional, personal and emotional impact of the sudden changes generated by the pandemic were factors that weighed so that the home office and alternative working hours in times of crisis should be better evaluated for an adaptation that avoids generating emotional difficulties for employees, especially in times of stress, anxiety and uncertainty, as was the case with the pandemic.
\end{abstract}

\footnotetext{
1 Graduanda do Curso de graduação em Publicidade e Propaganda da UNISATC

2 Professor da UNISATC, mestrando do PPGTIC UFSC.
} 


\title{
RECIMA21 - REVISTA CIENTÍFICA MULTIDISCIPLINAR
}

\author{
O IMPACTO DA PANDEMIA DO NOVO CORONAVÍRUS NA JORNADA DE TRABALHO \\ DOS PROFISSIONAIS DE PUBLICIDADE E PROPAGANDA \\ Josiene Severo Noronha, Davi Carrer
}

KEYWORDS: Home office. Advertising and marketing. Coronavirus.

\section{INTRODUÇÃO}

$\mathrm{O}$ ano de 2020 foi marcado por uma pandemia que assolou o mundo inteiro. A preocupação com a saúde e com a economia fez com que as empresas e os empregos sofressem transformações para se adaptarem ao momento. As pessoas foram instruídas a entrar em estado de quarentena ou isolamento social ${ }^{1} \mathrm{e}$ as suas relações com o emprego tiveram que mudar: passaram a trabalhar de casa. Foi o caso dos profissionais de comunicação que, por meio da tecnologia e do compartilhamento em rede, puderam garantir que o seu trabalho tivesse continuidade de dentro de casa.

Apesar do home office ou teletrabalho não ser uma novidade e possuir uma lei que o regulamente, a sua implementação durante a pandemia precisou ser rápida e, consequentemente, improvisada. Empresas que não haviam implementado o home office tiveram que se adaptar e criar soluções para continuar se comunicando de forma eficiente com a equipe, enquanto os colaboradores tiveram que adaptar locais de trabalho em casa e, também, sua rotina no lar.

O presente estudo teve por objetivo geral entender e analisar quais foram as mudanças e adaptações que os profissionais que trabalham em agências de Publicidade e Propaganda tiveram que enfrentar, e o objetivo específico foi analisar quais foram os impactos imediatos que sentiram em suas vidas e se o home office pode vir a ser uma realidade desses profissionais ou se foi algo apenas momentâneo.

Para responder a esse objetivo foi realizada uma revisão de literatura em relação aos temas: home office antes e depois da pandemia; a estrutura de uma agência de Publicidade e os prós e contras da implementação do home office nesse setor; e como são organizados o mercado e a jornada de trabalho nas organizações. Além disso, foi realizada uma pesquisa com 21 perguntas que foi respondida por 43 pessoas que trabalham em agências de Santa Catarina, a fim de validar as informações relacionadas ao home office. A pesquisa, quanto a sua natureza, é básica e foi aplicada sob forma de abordagem qualitativa.

\section{HOME OFFICE: COMO ERA ANTES E O QUE MUDOU DURANTE A PANDEMIA}

Em 2017, o teletrabalho foi regulamentado através de mudanças na Consolidação das Leis do Trabalho (CLT), mediante a Lei 13.467/2017. O capítulo II-A no Art. 75-B diz que "considera-

\footnotetext{
${ }^{1}$ Quarentena: tipo de reclusão aplicado a um grupo de pessoas sadias, mas que podem ter sido contaminadas por agente causador de alguma doença, evitando que ela se espalhe. Isolamento social: ato voluntário ou involuntário de manter-se isolado do convívio com outros indivíduos ou com a sociedade.
} 


\section{RECIMA21 - REVISTA CIENTÍFICA MULTIDISCIPLINAR}

O IMPACTO DA PANDEMIA DO NOVO CORONAVÍRUS NA JORNADA DE TRABALHO DOS PROFISSIONAIS DE PUBLICIDADE E PROPAGANDA Josiene Severo Noronha, Davi Carrer

se teletrabalho a prestação de serviços preponderantemente fora das dependências do empregador, com a utilização de tecnologias de informação e de comunicação que, por sua natureza, não se constituam como trabalho externo". Para que o teletrabalho ou, como é conhecido, o home office aconteça, essas tecnologias são um ponto de extrema importância, pois geralmente o colaborador precisa de equipamentos para realizar o seu ofício longe do escritório, utilizando de computadores ou de celulares conectados à internet para realizar as tarefas remotamente. Outro ponto que caracteriza o home office é o local de trabalho, pois não precisa ser necessariamente em casa, podendo o trabalho ser realizado em espaços como cafés, hotéis ou qualquer outro local que não seja necessariamente de propriedade da empresa contratante (DUARTE, 2008).

Segundo o Instituto Brasileiro de Geografia e Estatística (IBGE), o número de brasileiros que trabalhavam em casa entre os anos de 2018 e 2019 era de 3,8 milhões de brasileiros. O home office, destacou o IBGE, teve queda de 2,1\% entre 2012 e 2014, cresceu 7,3\% em 2015, e voltou a ter queda de 2,2\% em 2016. Já entre 2017 e 2018, cresceu em 21,1\% (SILVEIRA, 2019). Em pesquisa realizada com mil pessoas no ano de 2017, a Robert Half, empresa global de consultoria de recursos humanos, apontou que $96 \%$ dos profissionais brasileiros são favoráveis ao home office. Entre os principais fatores a favor estão o aumento de produtividade $(29,4 \%)$, a melhora na qualidade de vida $(25,5 \%)$ e o equilíbrio entre vida pessoal e profissional $(21,6 \%)^{2}$

Em 2020, reacendeu-se a discussão sobre o home office devido a pandemia do novo coronavírus, o Covid-19. Empresas se viram obrigadas a pararem suas atividades por conta do risco à saúde dos colaboradores e de toda a população contraírem infecções respiratórias geradas pelo vírus. Um estudo, publicado no The Wall Street Journal ${ }^{3}$, realizado pela empresa norte-americana Deloite citava o home office como tendência, porém em 2020 a necessidade de ficar em casa devido ao Covid-19, acelerou o processo de adaptação das empresas (PHELIPE; MEDEIROS, 2020).

Além do home office, que algumas empresas adotaram como medida durante a pandemia, o Diário Oficial da União (DOU) publicou medida provisória instituindo o Programa Emergencial de Manutenção do Emprego e da Renda, tratando da aplicação de medidas trabalhistas para o enfrentamento do estado de calamidade pública a que o Brasil foi submetido, devido ao novo coronavírus. A Medida Provisória (MP) 936/2020, válida durante todo o período de estado de calamidade, instituiu novas regras para as empresas, entre elas a redução proporcional de jornada de trabalho e o pagamento do Benefício Emergencial de Preservação do Emprego e da Renda. O empregador, através dessa MP, pode realizar acordo com os colaboradores para reduzir a jornada de trabalho e salários em $25 \%, 50 \%$ ou $70 \%$ por até três meses, ficando o restante do salário sob

2 Link da pesquisa: https://www.roberthalf.com.br/imprensa/maioria-dos-profissionais-e-favor-de-trabalhar-decasa

${ }^{3}$ Estudo: https://www2.deloitte.com/br/pt/pages/human-capital/articles/tendencias-capital-humano.html 
responsabilidade do governo, que deve pagar com uma parte do seguro-desemprego, que é direito do trabalhador. Outra medida é a suspensão temporária do contrato dos colaboradores pelo prazo máximo de sessenta dias. Essa MP leva em conta o tamanho da empresa, a quantidade de colaboradores, e quanto cada um recebe a fim de determinar o valor do seguro desemprego que tem seu pagamento sob encargo do governo, sendo que o mesmo pode ser de $100 \%$ ou dividido entre empresa e governo. (SENADO FEDERAL, 2020)

Segundo matéria publicada na revista Exame, os colaboradores estiveram atentos para o que diziam os seus empregadores em relação às medidas tomadas devido à pandemia. E, para que as empresas pudessem tomar decisões, elas recorreram às orientações do governo local, Organização Mundial da Saúde (OMS) e o Centro de Controle e Prevenção de Doenças (CCPD), a fim de determinar seus passos. De acordo com o presidente da Sociedade Brasileira de Teletrabalho e Teleatividades (Sobratt), Luis Otávio Camargo Pinto, a situação de teletrabalho pode ser adotada pelas empresas não apenas em casos de pandemia, como no Covid-19, mas como plano de contingenciamento em situações emergenciais, como foi o caso das enchentes enfrentadas pelos estados de Minas Gerais, São Paulo, Rio de Janeiro e Espírito Santo, por exemplo. ${ }^{4}$

\subsection{O MERCADO PUBLICITÁRIO E A IMPLEMENTAÇÃO DO HOME OFFICE.}

A área de Publicidade e Propaganda emprega profissionais que exercem a arte de criar, planejar, produzir e veicular campanhas publicitárias. "A escolha de cada profissional para compor a organização depende do serviço específico que se pretende prestar, do tamanho da empresa e do seu plano estratégico de crescimento." (BONA, 2012)

Segundo Bona (2012), em uma agência existem áreas distintas, cada uma com funções, missões, responsabilidades, desafios e problemas que devem receber a devida atenção. Atendimento é o setor ou profissional que vai atrás de contas para a agência, sendo responsável pelo contato direto com o cliente, construindo com esse cliente o briefing e tendo uma relação de confiança com o mesmo, sendo capaz de conhecer e tomar decisões junto com o cliente que sejam ideais para o seu negócio. Por esses motivos, o atendimento está em contato direto com o cliente, seja por telefone, e-mail ou reuniões presenciais. (BONA, 2012)

Outro setor da agência é o de planejamento. Esse setor é o responsável pela realização das pesquisas e coletas de materiais com base no briefing recebido. Com base nisso, o planejamento pode determinar as estratégias que serão realizadas para determinado cliente. (BONA, 2012)

\footnotetext{
${ }^{4}$ Entrevista no site Agência Brasil: https://agenciabrasil.ebc.com.br/saude/noticia/2020-03/empresas-adotamhome-office-por-conta-do-coronavirus
} 


\section{RECIMA21 - REVISTA CIENTÍFICA MULTIDISCIPLINAR}

O IMPACTO DA PANDEMIA DO NOVO CORONAVÍRUS NA JORNADA DE TRABALHO DOS PROFISSIONAIS DE PUBLICIDADE E PROPAGANDA Josiene Severo Noronha, Davi Carrer

Um setor da agência, responsável por reunir os dados e informações e transformá-las em soluções de comunicação é o setor de criação. Na equipe de criação, o redator e a arte andam juntos, formando a dupla de criação. Um dos principais problemas que essa equipe enfrenta é a questão de prazos, geralmente impostos pelo atendimento e, também, a falta de informação do briefing que acaba dificultando a assertividade do trabalho. (BONA, 2012)

Outro profissional de uma agência é o mídia e a missão dele é, com base nas pesquisas e diretrizes do planejamento, sugerir e selecionar veiculações de mídia, negociando os melhores espaços e valores nos meios de comunicação.

De posse do plano de aplicação do orçamento, sua missão, então é cruzar as melhores inserções com os seus respectivos valores de veiculação tentando negociar, a partir da demanda que a própria agência apresenta ao veículo, descontos interessantes que façam com que o cliente tenha possibilidade de obter maior exposição nos melhores horários/locais, com o mesmo investimento, obtendo os melhores resultados. (BONA, 2012, p. 54)

Para funcionar bem, uma agência também conta com o setor administrativo e de apoio. O setor administrativo possui um ou mais profissionais responsáveis pelas contas a pagar e receber, compras, orçamentos, contratos e outros documentos legais. Já o apoio conta com pessoas responsáveis pela manutenção, almoxarifado e limpeza. (BONA, 2012)

Em algumas agências também pode existir o profissional de tráfego que, basicamente, fica responsável pelo cumprimento dos prazos entre os demais setores.

Seguindo o fluxo de trabalho de uma agência, o Atendimento traz o job ou a
campanha para a equipe, repassa as principais informações ao Planejamento, que,
por sua vez, repassa aos criativos suas ideias. A Criação prepara um rascunho das
possibilidades, o Atendimento leva ao cliente as ideias de solução e criação; depois
que estas são aprovadas, com ou sem alterações, entra em cena o Tráfego, que
distribui as tarefas entre os departamentos de Mídia, Criação, Arte-finalização e
Produção, além de acompanhar os procedimentos para que sejam finalizados no
tempo necessário para a veiculação negociada pelo Mídia. (BONA, 2012, p. 60)

Segundo estudo realizado por Silva (2018), para que o profissional de comunicação trabalhe em home office é importante verificar as vantagens e desvantagens dessa prática para 0 trabalhador, para a empresa e a sociedade. Entre as vantagens para o trabalhador estão a redução do tempo de deslocamento da casa para a empresa, a economia no combustível, a flexibilização do horário e do local de trabalho, mais conforto e mais tempo para conciliar a vida profissional e pessoal.

Para as empresas há uma economia, pois reduz os custos com imobiliário, vale transporte para colaboradores. Além disso, percebe-se uma maior produtividade e facilidade na hora 


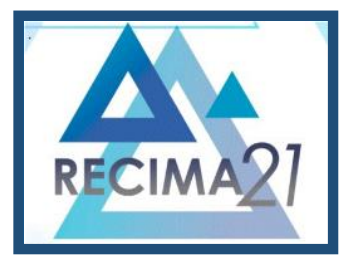

\section{RECIMA21 - REVISTA CIENTÍFICA MULTIDISCIPLINAR}

O IMPACTO DA PANDEMIA DO NOVO CORONAVÍRUS NA JORNADA DE TRABALHO DOS PROFISSIONAIS DE PUBLICIDADE E PROPAGANDA Josiene Severo Noronha, Davi Carrer

de recrutar novos colaboradores. Para a sociedade os aspectos positivos são a geração de novos empregos, o descongestionamento dos centros urbanos e a redução da poluição.

O home office possui algumas desvantagens para 0 trabalhador. $O$ isolamento social devido à redução do contato entre os colegas de trabalho é uma delas. A falta de estrutura em casa, dificuldade de defesa dos interesses laborais e profissionais. Além disso, muitas vezes pode se tornar complicado separar a vida profissional da vida pessoal.

A dificuldade que se apresenta para a empresa é que o colaborador pode não estar disponível de forma imediata. A empresa pode ter custos extras também em equipamentos e energia necessários para garantir que o colaborador possa ficar em trabalho remoto. (SILVA, 2018)

Em um estudo feito pelo publicitário e apresentador do podcast "Propaganda não é só isso aí" Lucas Schuch, foram entrevistados 435 profissionais de agências do Brasil sobre trabalho remoto durante a pandemia do Covid-19. A pesquisa intitulada "Home Office - Tá bom para todo mundo mesmo?"5 mostrou que o trabalho remoto durante a pandemia gerou efeitos negativos sobre os profissionais de publicidade.

Quando perguntados se o home office era uma prática da empresa, $84 \%$ dos entrevistados disseram que para a empresa onde trabalham essa prática não era usual e, apenas $15 \%$ disseram que a empresa aceitava que os trabalhadores fizessem home office em determinados dias da semana. Para 94\% dos respondentes, o trabalho remoto somente foi adotado devido ao isolamento social durante a pandemia.

Devido ao escasso tempo que tiveram para se preparar para a nova realidade, somente metade dos entrevistados relataram estar preparados para o home office, enquanto a outra metade mostrou não estar preparada e, entre as queixas, estavam a ausência de um local adequado para o trabalho em casa, a falta de contato humano e os horários estendidos.

Sobre o desempenho profissional dos entrevistados: $32 \%$ disseram estar produzindo mais, $31 \%$ no mesmo volume e $35 \%$ abaixo do rendimento normal, baseado no quanto produziam na fase anterior ao isolamento social. Outro ponto foi a cobrança em relação ao trabalho, sendo que, de cada dez participantes da pesquisa, quatro relataram esse fator. Questionados sobre sua saúde mental, $65 \%$ disseram estar menos saudáveis mentalmente, enquanto $20 \%$ relataram se sentir mais saudáveis e 14\% não perceberam alterações em relação à sua saúde mental.

\footnotetext{
5 Pesquisa veiculada pela Meio e Mensagem no link: https://www.meioemensagem.com.br/home/comunicacao/2020/04/24/home-office-publicitarios-relatam-perda-derendimento-e-saude-mental.html
} 


\section{RECIMA21 - REVISTA CIENTÍFICA MULTIDISCIPLINAR}

O IMPACTO DA PANDEMIA DO NOVO CORONAVÍRUS NA JORNADA DE TRABALHO DOS PROFISSIONAIS DE PUBLICIDADE E PROPAGANDA Josiene Severo Noronha, Davi Carrer

Em relação a salários e benefícios devido à situação econômica gerada pela pandemia, a pesquisa mostrou que $49 \%$ não sofreram cortes de salário, 24\% tiveram benefícios cortados, $18 \%$ relataram que, mesmo antes, já não tinham benefícios e 7\% ganharam benefícios acrescidos ao seu salário. Quando perguntados sobre a postura da agência em relação à gestão de pessoas, 33\% disseram que a agência parecia estar preocupada com sua situação pessoal, 56\% notaram que a agência estava mais preocupada com os clientes do que com os colaboradores e $40 \%$ notaram um equilíbrio da preocupação entre as duas partes (JULIO, 2020).

Segundo Silva (2018, p. 52) é importante considerar algumas consequências antes de implementar tendências que envolvam a rápida disseminação da tecnologia e formas de contrato das condições de trabalho. Algumas consequências são a tendência ao isolamento; não conseguir separar o trabalho e a atenção à família; a administração do tempo e a tendência a procrastinar; o planejamento e o monitoramento das atividades; os aspectos motivacionais e o sofrimento no trabalho.

Os teletrabalhadores, de maneira geral, lidam com um contexto de trabalho ainda pouco convencional, abordando tanto as vantagens quanto as dificuldades inerentes à prática do teletrabalho, e ainda precisam levar em consideração as questões referentes à própria saúde física e mental, preocupando-se com os aspectos ergonômicos, fisiológicos, sociais e psicológicos que impactam no desempenho, na produtividade, na realização profissional e na saúde global do indivíduo. (SILVA, 2018, p. 53)

\subsubsection{DIFERENTES FORMAS DE ORGANIZAÇÃO DO MERCADO E JORNADA DE TRABALHO}

$\mathrm{Na}$ Era Industrial, as organizações viam os colaboradores apenas como recursos organizacionais. A Era da Informação está transformando essa visão, pois atividades humanas que antes eram consideradas repetitivas estão passando a ser criativas e inovadoras. Segundo Chiavenato (2009, p. 71), "antes as práticas de RH eram padronizadas e estereotipadas a fim de garantir a homogeneidade de comportamento". Atualmente a diversidade está em evidência e as empresas buscam capital humano com competências pessoais, e não apenas profissionais. Os cargos dentro de empresas estão passando por redefinições e estão funcionando em conjunto, com todos trabalhando em equipes. (CHIAVENATO, 2009)

Chiavenato (2009) diz que as empresas estão sofrendo transformações: organizações convencionais com sistemas burocráticos estão mudando e focando suas energias e recursos em inteligência competitiva. O capital intelectual está trazendo formas inovadoras das organizações pensarem e agirem. A administração tradicional está destinada a representar $20 \%$ do valor de uma empresa. Os outros $80 \%$ dependem de redes de network, empregos terceirizados, flexibilidade de horários em que os trabalhadores poderão realizar seus trabalhos de casa (home office), pois as empresas estão presentes no meio virtual, possibilitando essa realidade. 


\section{RECIMA21 - REVISTA CIENTÍFICA MULTIDISCIPLINAR}

O IMPACTO DA PANDEMIA DO NOVO CORONAVÍRUS NA JORNADA DE TRABALHO DOS PROFISSIONAIS DE PUBLICIDADE E PROPAGANDA Josiene Severo Noronha, Davi Carrer

"Megasoftwares irão revolucionar a organização das empresas. Com isso, a parte tradicional das organizações passará por uma total revolução, ficando a atividade burocrática humana praticamente zerada e transferida para a máquina. (CHIAVENATO, 2009, p. 90)". Em consequência de tudo isso, os talentos humanos estarão disputados, e poderão escolher as empresas que ofereçam um ambiente humanizado, propício ao seu desenvolvimento e com recompensas justas ao seu real valor.

De acordo com Chiavenato (2009), para que ocorra mudanças nas organizações, algumas condições deverão ser proporcionadas às pessoas, entre elas o desenvolvimento de amplas bases de experiências e networking ${ }^{6}$, gerando oportunidades mais amplas na carreira.

A força de trabalho tenderá a ter um relacionamento diferente e não mais dependente de um único empregador. As pessoas terão relações de curto tempo ao longo de suas carreiras nas quais deverão contribuir com conhecimentos e expertise em resposta a necessidades específicas dos negócios. Elas deverão trabalhar como se fossem as proprietárias do negócio cujo cliente é a corporação. (CHIAVENATO, 2009, p. 439)

Gerenciar a própria carreira é uma competência que as pessoas estão precisando adquirir. Visando as atividades atuais em que trabalham e as futuras posições que desejam ocupar, os profissionais estão se comprometendo em buscar qualificações, conhecimentos e competências. O que as empresas estão fazendo por esses profissionais que desejam aprimoramento é proporcionar infraestruturas que garantam o aprendizado contínuo. (CHIAVENATO, 2009)

A jornada de trabalho é o montante de horas diárias, semanais ou mensais de cada trabalhador. Com o contexto de trabalho sofrendo mudanças, a jornada também tem sido alterada em alguns casos como meio de atrair e reter colaboradores. Segundo Chiavenato (2009), os programas de trabalho alternativos e flexíveis podem ser definidos como semana de trabalho reduzida; horário flexível de trabalho; trabalho compartilhado; e trabalho remoto.

A semana de trabalho reduzida é um programa que envolve tempo integral de trabalho a ser completado em menor tempo do que o padrão. A forma mais comum desse tipo de programa é cumprir quarenta horas em quatro dias de dez horas. A vantagem para o colaborador é permitir que ele tenha três dias consecutivos de descanso semanal. Para a empresa a vantagem é a redução de custos operacionais, a diminuição de absenteísmos e a melhora do desempenho por parte dos colaboradores. Os pontos negativos desse programa é o possível aumento de fadiga e eventuais problemas sindicais.

\footnotetext{
${ }^{6}$ Networking é uma palavra em inglês que indica a capacidade de estabelecer uma rede de contatos ou uma conexão com algo ou com alguém.
} 


\section{RECIMA21 - REVISTA CIENTÍFICA MULTIDISCIPLINAR}

O IMPACTO DA PANDEMIA DO NOVO CORONAVÍRUS NA JORNADA DE TRABALHO DOS PROFISSIONAIS DE PUBLICIDADE E PROPAGANDA Josiene Severo Noronha, Davi Carrer

O horário flexível de trabalho consiste em um tempo-núcleo que é um bloco central de tempo onde os colaboradores devem estar trabalhando e, fora desse horário, os colaboradores podem escolher as horas de trabalho diários, como chegar mais tarde no local do trabalho, sair cedo, e possuir liberdade para conciliar a carreira e a vida pessoal.

Trabalho compartilhado consiste em duas pessoas exercendo a mesma função na empresa, porém dividindo a jornada diária. O mesmo cargo é de período integral, porém uma pessoa faz meio período e a outra o restante.

Trabalho remoto seria o freelancer, onde o trabalho é realizado de casa. As pessoas que optam por essa modalidade possuem a alternativa do autoemprego que é uma tendência e tem se tornado muito comum devido ao alto índice de desemprego e a necessidade de aumentar a renda. Os profissionais que decidem por essa modalidade tendem a aprimorar os seus serviços, buscando conhecimento técnico através de cursos e qualificações para oferecer ao mercado serviços com preços competitivos, agilidade no trabalho e custos menores ao empregador, já que o mesmo não precisa arcar com outras despesas que um colaborador dentro da empresa exigiria. $O$ trabalho remoto traz algumas vantagens para o profissional como liberdade para trabalhar em casa, não precisar de transporte, não ter distrações, aumentando sua produtividade e a sensação de ter o próprio negócio, dispondo de mais tempo para si. Porém, autoemprego não é protegido por direitos trabalhistas e consequentemente não possui décimo terceiro salário, férias remuneradas e outros benefícios, o que acaba fazendo com que esses profissionais tenham que administrar a sua carreira para não trabalhar em excesso e ainda assim conseguir se organizar financeiramente.

\section{PROCEDIMENTOS METODOLÓGICOS}

Realizada a revisão de literatura referente ao home office, sabemos que o mesmo já havia sido sancionado mediante lei aprovada em 2017, porém a pesquisa aplicada visou responder a como se deu sua implementação durante a pandemia do novo coronavírus. Foi elaborado um questionário para entender como o profissional da área de comunicação, de preferência aquele que trabalha em agência de Publicidade e Propaganda, encarou o home office durante a quarentena.

O questionário foi criado e compartilhado com o auxílio da ferramenta Formulários Google $^{7}$ e enviado de maneira online, utilizando o aplicativo WhatsApp para pessoas que trabalham na área de comunicação, sendo a maioria de Criciúma, regiões vizinhas e alguns de Florianópolis.

O questionário contou com 21 perguntas, sendo vinte delas de múltipla escolha e uma pergunta aberta. Segundo Mascarenhas (2012, p. 58), "com base nas informações obtidas, pode[-se]

\footnotetext{
${ }^{7}$ Link da pesquisa: https://forms.gle/5YBVncvd2TnNitM76
} 


\section{RECIMA21 - REVISTA CIENTÍFICA MULTIDISCIPLINAR}

O IMPACTO DA PANDEMIA DO NOVO CORONAVÍRUS NA JORNADA DE TRABALHO DOS PROFISSIONAIS DE PUBLICIDADE E PROPAGANDA Josiene Severo Noronha, Davi Carrer

fazer comparações entre os elementos estudados, bem como construir uma "ponte" entre teoria e prática [...] é importante voltar à hipótese formulada no início do estudo para ver se ela foi mesmo confirmada pelos dados".

Quarenta e três pessoas responderam o questionário e, entre esses, 32 eram mulheres e 11 homens, com idades entre 17 a 50 anos. Em relação à área de formação, 21 pessoas que responderam são da área de Design, oito de Publicidade, seis de Jornalismo e oito com formação não especificada. Dos que trabalham em agência de Publicidade são 24 respondentes e a maioria trabalha de um a três anos na área de comunicação.

FIG. 1 - PESQUISA

Sexo

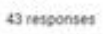

Oual a sua idade?

43 responses

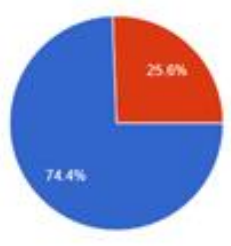

Cual a sua área de formaçăo?

43 responses

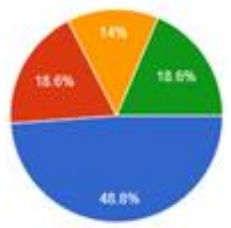

Quanto tempo voce trabalha na area de comunicaçio? 43 resposses

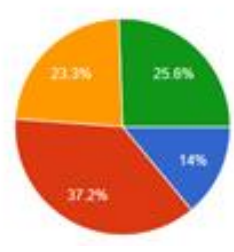

- Feminino
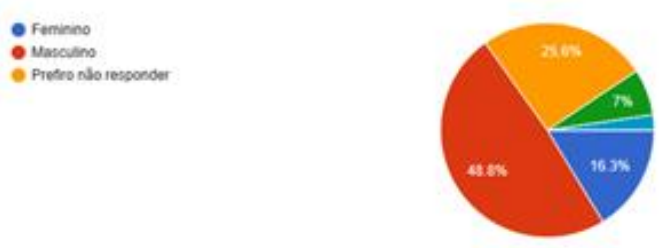

Vocé trabalha em agêneia de Publlicidade?

43 responses

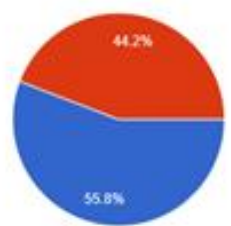

- 17 a 20 anes

- 21 a 25 ance

- 31 a 35 anoe

- 36 a 45 ance

- 40 a 50 ancos

- 31 inos ov mas

Fonte: Gráfico do Formulário Google

\subsection{HOME OFFICE DURANTE A PANDEMIA DE COVID-19}




\title{
RECIMA21 - REVISTA CIENTÍFICA MULTIDISCIPLINAR
}

\author{
O IMPACTO DA PANDEMIA DO NOVO CORONAVÍRUS NA JORNADA DE TRABALHO \\ DOS PROFISSIONAIS DE PUBLICIDADE E PROPAGANDA \\ Josiene Severo Noronha, Davi Carrer
}

Dando continuidade, os respondentes foram perguntados sobre o trabalho home office e como foi essa experiência durante a pandemia do Covid-19. Como visto em um estudo realizado pela empresa norte-americana Deloite ${ }^{8}$, o home office era visto como tendência nas organizações, porém o processo de implementação foi acelerado por conta da necessidade iminente de os colaboradores ficarem em casa devido a pandemia do Covid-19 (PHELIPE; MEDEIROS, 2020). Quando perguntados se eles trabalharam no sistema home office durante a pandemia, 42 respondentes disseram que sim, e apenas um, não. Antes da pandemia, as empresas de 23 entrevistados tinham feito algum período de home office em seu atual local de trabalho, e 20, não.

FIG. 2 - PESQUISA

Durante a pandemia do covid-19 voce trabalhou home office? 43 responses

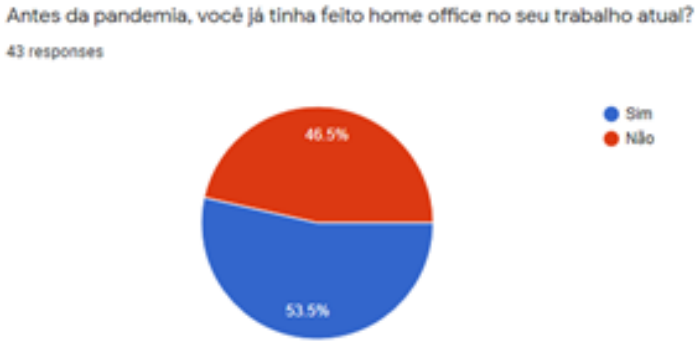

Fonte: Gráfico do Formulário Google

Conforme dito por Silva (2018), uma das desvantagens do home office é que o colaborador se sente isolado, devido ao distanciamento dos colegas de trabalho. Os respondentes que disseram sentir falta do convívio social com a equipe durante o home office foram 30 pessoas, e os que sentiram falta do local de trabalho foram 12. Esse distanciamento, juntamente com todo o contexto que a pandemia trouxe para a vida das pessoas, resultou na pergunta sobre como estava a saúde mental dos respondentes durante o home office, e 26 deles disseram notar que o psicológico foi abalado, 11 notaram uma melhora e outros 6 disseram não sentir alterações.

FIG. 3 - PESQUISA

\footnotetext{
${ }^{8}$ Link do estudo realizado: https://www2.deloitte.com/br/pt/pages/human-capital/articles/tendencias-capitalhumano.html
} 


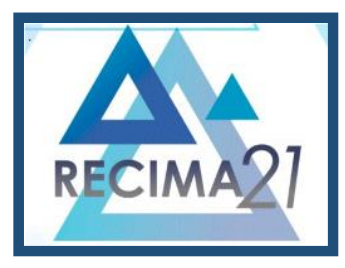

\section{RECIMA21 - REVISTA CIENTÍFICA MULTIDISCIPLINAR}

O IMPACTO DA PANDEMIA DO NOVO CORONAVÍRUS NA JORNADA DE TRABALHO DOS PROFISSIONAIS DE PUBLICIDADE E PROPAGANDA Josiene Severo Noronha, Davi Carrer

Do que sentiu mais falta no home otfice? 42 responses

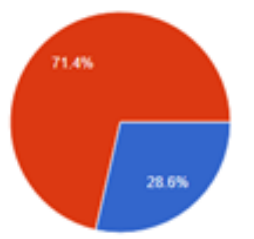

Como esta sua saúde mental trabalhando em home office? 43 responses

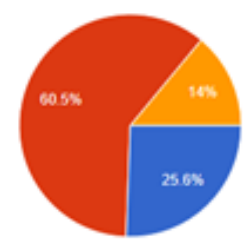

- Mas tosdiver Sem aneracilo

Fonte: Gráfico do Formulário Google

Outros problemas pontuados por Silva (2018) são a falta de estrutura, pois muitos têm dificuldade em ter local adequado para trabalho em casa. Na pesquisa realizada 35 disseram ter um escritório e local adequado dentro de casa para trabalhar e oito não tinham local apropriado. Muitos não possuem computadores adequados para a função e pode haver dificuldade com o provedor de internet e/ou o recebimento dos materiais remotos necessários para o trabalho. Na pesquisa efetuada, 26 dos entrevistados relataram dificuldade de acesso remoto como internet funcionando adequadamente e acesso ao servidor da empresa, enquanto os outros 17 disseram não ter problemas quanto a isso.

FIG. 4 - PESQUISA

Você tem um ambiente adequado pra trabalhar em casa? 43 responses
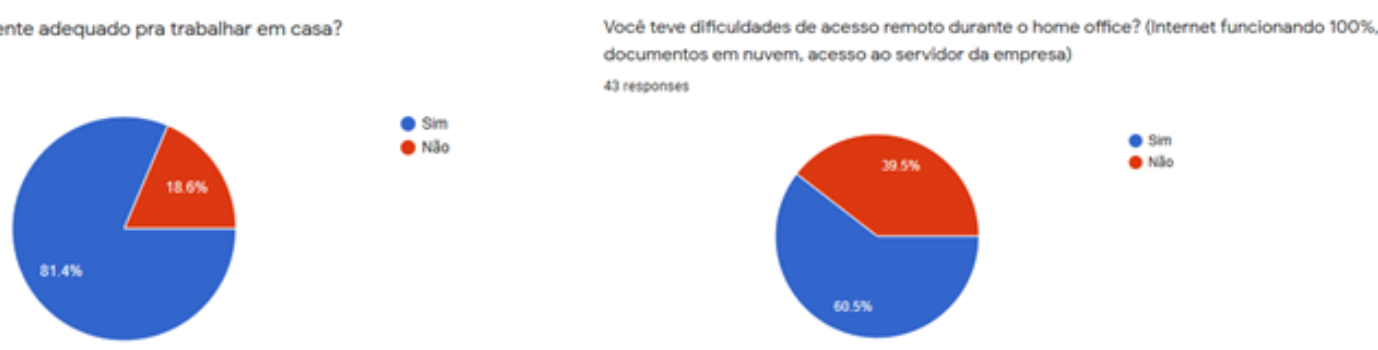

Fonte: Gráfico do Formulário Google

Conforme o estudo do publicitário Lucas Schuch já havia informado, o trabalho remoto durante a pandemia pode ter gerado efeitos negativos nos profissionais, além disso podem ter criado uma certa dificuldade de separar o trabalho da vida pessoal. Na pesquisa, os que disseram que trabalham mais durante o home office foram 31 , contra outros 12 que não viram aumento no trabalho. 25 pessoas disseram que o home office gerou confusão entre trabalho, tarefas de casa e hobbies, e os outros 18 disseram não. 


\section{RECIMA21 - REVISTA CIENTÍFICA MULTIDISCIPLINAR}

\section{O IMPACTO DA PANDEMIA DO NOVO CORONAVÍRUS NA JORNADA DE TRABALHO DOS PROFISSIONAIS DE PUBLICIDADE E PROPAGANDA Josiene Severo Noronha, Davi Carrer}

FIG. 5 - PESQUISA

Vocè acha que trabalhou mais durante o home office? 43 responses
Estar em casa gerou confusāo entre trabalho, tarefas de casa e hobbles? 43 cesponse:
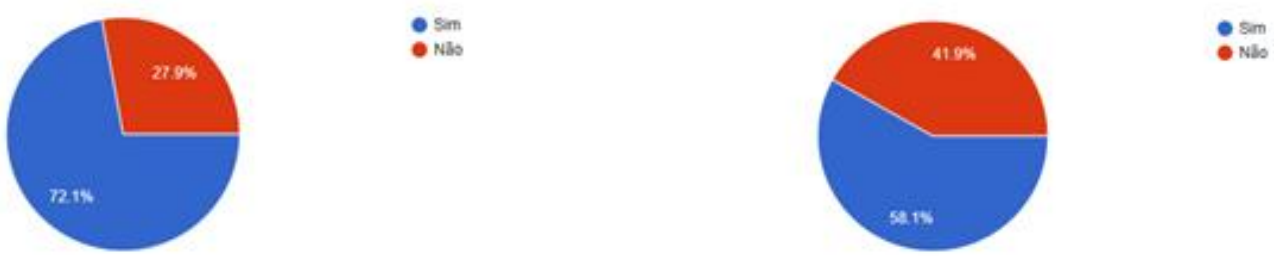

Fonte: Gráfico do Formulário Google

Segundo Silva (2018), o colaborador que trabalha em home office tem mais facilidade para procrastinar, ou seja, deixar tarefas para resolver depois. Na pesquisa realizada, quando questionado aos respondentes como foi o seu desempenho em relação às tarefas, 23 deles disseram que 0 desempenho permaneceu o mesmo de quando trabalhavam no interior da empresa, 10 responderam que seu desempenho ficou abaixo da média, e outros 10 aumentaram o desempenho trabalhando em casa.

FIG. 6 - PESQUISA

Comparado ao trabalho em equipe no interior da empresa, como você considera o seu desempenho no home office durante a pandemia?

43 responses

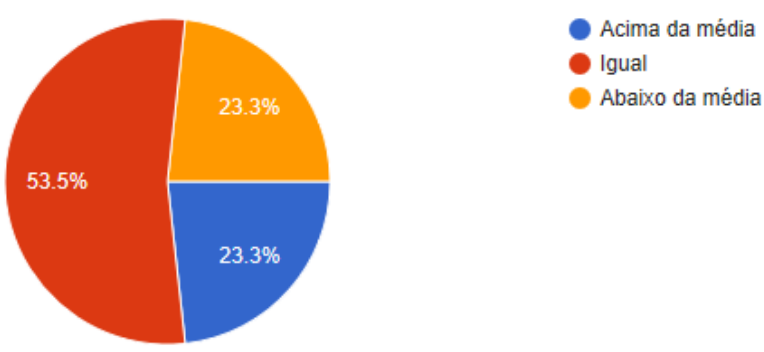

Fonte: Gráfico do Formulário Google

Quando questionados sobre a comunicação com os gestores e a equipe, 34 disseram que a comunicação foi eficaz e outros oito relataram dificuldades. A cobrança por entrega dos trabalhos continuou a mesma para 25 pessoas, já 14 delas disseram que a cobrança aumentou, e quatro, que diminuiu.

FIG. 7 - PESQUISA 


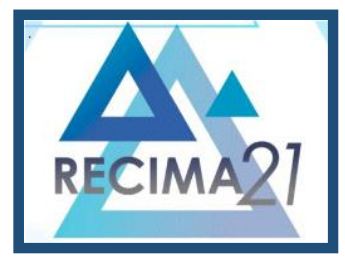

\section{RECIMA21 - REVISTA CIENTÍFICA MULTIDISCIPLINAR}

O IMPACTO DA PANDEMIA DO NOVO CORONAVÍRUS NA JORNADA DE TRABALHO DOS PROFISSIONAIS DE PUBLICIDADE E PROPAGANDA Josiene Severo Noronha, Davi Carrer

Durante o home office, voct conseguiu se comunicar de maneira efficaz com os seus gestores ea equipe para dar continuidade sos trabalhos?

42 esesponses

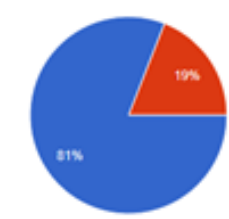

$\bullet \sin$
Durante o home office voce fol mals cobrado pelos chefes de equipe? 43resconses

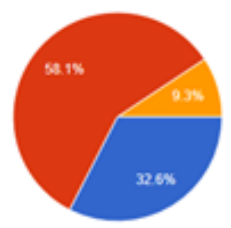

Fonte: Gráfico do Formulário Google

Silva (2018) diz em seu estudo sobre o home office que, para as empresas, pode haver uma economia, pois há diminuição de gastos com vale transporte e outros tipos de benefícios oferecidos para os colaboradores. Dos respondentes, 40 pessoas disseram que economizaram com alimentação e transporte. Em contrapartida, gastos extras com equipamentos e energia necessários para que o colaborador possa trabalhar, podem ocorrer. Os colaboradores que disseram ter algum tipo de apoio da agência durante o home office foram 28 e outros 15 não precisaram ou não foi oferecido.

FIG. 8 - PESQUISA

Você economizou, nesse periodo, devido ao home office? (alimentaçẳ, transporte, etc) 43 responses
A agència onde voces trabalha te ofereceu apoio durante o home office? 43 responses
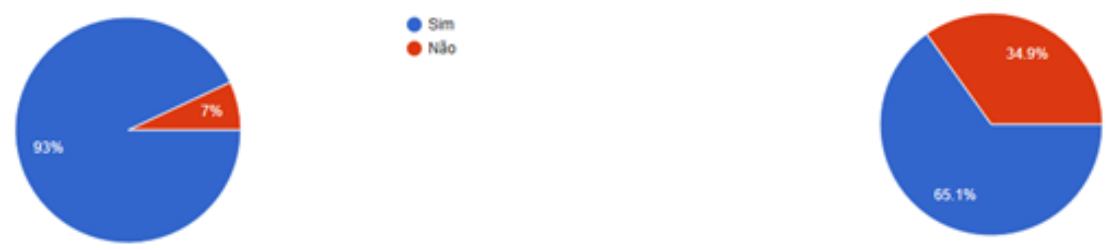

Fonte: Gráfico do Formulário Google

\subsubsection{AGÊNCIAS DE PUBLICIDADE E AS JORNADAS DE TRABALHO ALTERNATIVAS}

Fazendo uma correlação entre o mercado publicitário e a organização de jornada de trabalho, sabemos que o setor de atendimento é o que tem um contato maior com os clientes e a equipe. Segundo Bona (2012), o atendimento é aquele que traz a conta do cliente para a agência e está sempre disponível para tirar as dúvidas da equipe junto aos clientes. Esse setor é responsável 
pelo desenvolvimento do briefing e o mesmo passa para o setor de planejamento que fará as devidas pesquisas e coleta de informações para passar para a equipe de criação desenvolver. Para que o trabalho desses setores não seja prejudicado e como uma alternativa para a agência que não é optante pelo sistema home office, pode ser usado a semana de trabalho reduzida que, segundo Chiavenato (2009), permite que o colaborador cumpra as quarenta horas de trabalho em quatro dias de dez horas, dando ao colaborador a possibilidade de ter três dias de descanso semanal.

Algumas agências já trabalham com o horário flexível de trabalho que, segundo Chiavenato (2009), consiste em um tempo-núcleo, ou seja, um bloco de horas que os colaboradores devem cumprir, sendo possível optar por fazer seu próprio horário, chegando mais tarde no trabalho por exemplo, ou saindo um pouco mais cedo, mas cumprindo os horários semanais estipulados. Essa jornada geralmente é aplicada ao setor de criação.

O profissional de mídia seria um dos que mais poderiam se beneficiar do sistema home office pois, como diz Duarte (2008), esse sistema se caracteriza pelo trabalho que pode ser feito fora das dependências da empresa e, como cabe ao profissional de mídia sugerir e selecionar veiculações de mídia e negociar com os fornecedores, esse trabalho poderia ser feito de qualquer lugar. E, para o caso de algumas agências, existe o profissional de tráfego, que "[...] distribui as tarefas entre os departamentos de Mídia, Criação, Arte-finalização e Produção, além de acompanhar os procedimentos para que sejam finalizados no tempo necessário para a veiculação negociada pelo Mídia." (BONA, 2012, p. 60). Esse profissional é forte candidato ao home office também por não precisar necessariamente estar no interior da empresa para estipular e cumprir prazos entre os demais setores.

Já os profissionais do administrativo e apoio podem se beneficiar do sistema de trabalho compartilhado que é quando duas pessoas exercem a mesma função, porém dividem a jornada, como explica Chiavenato (2009).

Essas jornadas de trabalho podem ser opções para as agências de Publicidade que não implementaram o home office ou que os seus colaboradores não estão acostumados, pois são alternativas que permitem a flexibilização das jornadas de trabalho e que já ajudam os profissionais que não podem se ausentar totalmente do interior da agência, principalmente por que, quando questionados, 25 pessoas disseram que preferiam trabalhar no interior da empresa e somente 18 no home office.

\section{CONCLUSÕES}

Este artigo teve como objetivo principal analisar quais foram as mudanças e adaptações que os profissionais de agências de Publicidade tiveram que enfrentar para que o home office fosse estabelecido durante a pandemia do novo coronavírus. Assim como, analisar quais foram os 


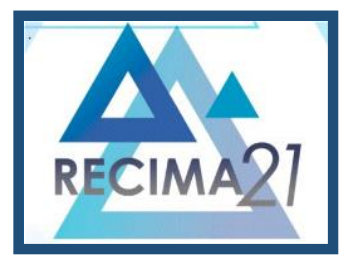

\section{RECIMA21 - REVISTA CIENTÍFICA MULTIDISCIPLINAR}

O IMPACTO DA PANDEMIA DO NOVO CORONAVÍRUS NA JORNADA DE TRABALHO DOS PROFISSIONAIS DE PUBLICIDADE E PROPAGANDA Josiene Severo Noronha, Davi Carrer

impactos imediatos que sentiram em suas vidas e se o home office pode vir a ser uma realidade desses profissionais ou se foi algo apenas momentâneo.

Ao longo do estudo ficou evidente que alguns autores exaltam o home office como uma boa prática para as empresas e para os colaboradores, mas as pesquisas realizadas dentro de um contexto específico, o da pandemia do novo coronavírus, em 2020, permitiu observar que o estresse e ansiedade gerados, mostrou que o sistema home office durante um contexto como este, acaba desestabilizando a saúde mental dos colaboradores.

Os resultados desse artigo mostraram que muitas dificuldades apresentadas pelos colaboradores durante o home office podem ter sido agravadas pela situação de incerteza e estresse gerados pela pandemia e, também, pela forma improvisada que o home office foi implementado pelas empresas. Não foi possível chegar a uma definição conclusiva de que o home office possa ser uma realidade para os profissionais pelos próximos anos, mas há muitos fatos que apontam que ele pode, sim, ser usado em diversos momentos, principalmente se for para preservar o emprego dos colaboradores e a saúde financeira da empresa. Além do home office, fica evidente que o uso de jornadas de trabalho alternativas pode ser praticado para dar aos colaboradores mais tempo para administrarem suas carreiras e vida pessoal.

Se faz importante frisar que esse estudo foi realizado durante o período de pandemia e, para verificar a viabilidade do home office e outros tipos de jornada de trabalho alternativas em um contexto mais saudável, recomenda-se a importância de fazer outros estudos, com diferentes contextos. Além disso, é importante ampliar as amostras, restringir as respostas aos profissionais que trabalham em cada um dos setores da agência, para saber realmente qual o tipo de jornada é o ideal para ser aplicada a cada um.

Além disso, é importante investir em estudos para analisar quais as ações que as empresas podem tomar para gerenciar melhor a quantidade de trabalho enviada para os profissionais em home office, visando também melhorar o acesso ao software da empresa, facilitando o recebimento e entrega dos trabalhos por parte dos colaboradores.

Esse artigo, então, foi importante para verificar quais os aspectos positivos e negativos do home office para o colaborador durante a pandemia e para analisar as mudanças necessárias que, principalmente a empresa, deve realizar para que as jornadas de trabalho possam beneficiar os colaboradores, aumentando assim a sua satisfação e, consequentemente, a satisfação dos clientes que, no caso das agências de Publicidade, serão impactados diretamente pelo bom funcionamento da empresa.

\section{REFERÊNCIAS}




\section{RECIMA21 - REVISTA CIENTÍFICA MULTIDISCIPLINAR}

O IMPACTO DA PANDEMIA DO NOVO CORONAVÍRUS NA JORNADA DE TRABALHO DOS PROFISSIONAIS DE PUBLICIDADE E PROPAGANDA Josiene Severo Noronha, Davi Carrer

AGÊNCIA BRASIL. Empresas adotam home-office por conta do coronavírus. Disponível em: https://agenciabrasil.ebc.com.br/saude/noticia/2020-03/empresas-adotam-home-office-por-conta-docoronavirus. Acesso em: 14 abr. 2020.

BONA, Nivea Canalli. Publicidade e propaganda: da agência à campanha. Curitiba: Intersaberes, 2012.

CHIAVENATO, Idalberto. Recursos Humanos: o capital humano das organizações. Rio de Janeiro: Elsevier, 2009.

DUARTE, Leonardo Gularte. Teletrabalho: um novo modelo de trabalho. Disponível em: https://ambitojuridico.com.br/edicoes/revista-59/teletrabalho-um-novo-modelo-de-trabalho/. Acesso em: 11 abr. 2020.

GO HOME. Reforma trabalhista e o Trabalho Remoto: o que muda para empresas e colaboradores. Disponível em: https://www.gohome.com.br/reforma-trabalhista-trabalho-remoto/. Acesso em: 11 abr. 2020.

GRANATO, Luíza. Como as empresas devem orientar seus funcionários sobre o coronavírus. Disponível em: https://exame.abril.com.br/carreira/como-as-empresas-devem-orientar-seusfuncionarios-sobre-o-coronavirus/. Acesso em: 14 abr. 2020.

JULIO, Karina Balan. Publicitários relatam perda de rendimento e saúde mental. Disponível em: https://www.meioemensagem.com.br/home/comunicacao/2020/04/24/home-office-publicitariosrelatam-perda-de-rendimento-e-saude-mental.html. Acesso em: 30 abr. 2020.

BRASIL. LEI № 13.467, DE 13 DE JULHO DE 2017. Disponível em: http://www.planalto.gov.br/ccivil 03/ ato2015-2018/2017/lei//13467.htm. Acesso em: 10 mar. 2020.

MASCARENAS, Sidnei Augusto. Metodologia Científica. São Paulo: Pearson Education do Brasil, 2012.

MINISTÉRIO DA SAÚDE. O que é coronavírus? (COVID-19). Disponível em: https://coronavirus.saude.gov.br/. Acesso em: 13 abr. 2020.

PHELIPE, André; MEDEIROS, Israel. Covid-19 muda a rotina do mercado de trabalho com o home office. Disponível em: https://www.correiobraziliense.com.br/app/noticia/economia/2020/03/21/internas economia,835717/c ovid-19-muda-a-rotina-do-mercado-de-trabalho-com-o-home-office.shtml. Acesso em: 13 abr. 2020.

ROBERT, HALF. Maioria dos profissionais é a favor de trabalhar de casa. Disponível em: https://www.roberthalf.com.br/imprensa/maioria-dos-profissionais-e-favor-de-trabalhar-de-casa.

Acesso em: 02 mar. 2020.

SENADO NOTÍCIAS. MP prevê novas regras para redução de jornada e salário e suspensão de contrato. Disponível em: https://www12.senado.leg.br/noticias/materias/2020/04/02/mp-preve-novasregras-para-reducao-de-jornada-e-salario-e-suspensao-de-contrato. Acesso em: 13 abr. 2020.

SILVA, Guilherme Elias. Teletrabalho: nova configuração de trabalho flexível e possíveis efeitos à subjetividade e saúde mental dos teletrabalhadores. Revista Espaço Acadêmico, n. 209, p. 44-55, 2018.

SILVEIRA, Daniel. Home office bateu recorde no Brasil em 2018, diz IBGE. Disponível em: https://g1.globo.com/economia/concursos-e-emprego/noticia/2019/12/18/home-office-bateu-recordeno-brasil-em-2018-diz-ibge.ghtml. Acesso em: 02 mar. 2020. 